\title{
Determinants of burnout syndrome among nurses in Cameroon
}

\author{
Clarence Mbanga' ${ }^{1}$, Haman Makebe ${ }^{2}$, Divine Tim ${ }^{3,4,5}$, Steve Fonkou ${ }^{6,7}$, Louise Toukam² and Tsi Njim ${ }^{4 *}$ (D
}

\begin{abstract}
Objectives: Burnout syndrome is common amongst medical personnel. The objective of this study was to identify determinants of burnout syndrome among nurses in the north west and south west regions of Cameroon.

Results: A cross-sectional analysis during the months of January-June 2018 was carried out recruiting nurses consecutively after consent from state-owned and private hospitals in the English-speaking regions of Cameroon. Burnout was assessed using the Oldenburg Burnout Inventory (OLBI). Univariable regression analysis used to identify determinants of burnout syndrome among 143 nurses (mean age $29.75 \pm 6.55$ years) showed that being in a personal relationship (Beta $=2.25$ ) significantly explained $3.8 \%$ of the variation in burnout $\left(R^{2}=3.8, F(1,125)=4.89, p=0.029\right)$.
\end{abstract}

Keywords: Burnout syndrome, Nurses, Prevalence, Cameroon, Oldenburg Burnout Inventory

\section{Introduction}

Burnout syndrome is a psychological state during which an individual experiences high levels of emotional exhaustion and disengagement from their work due to prolonged exposure to work environment stressors [1, 2]. It has been recognised by the World Health Organization (WHO) as a mental health problem and defined as a "state of vital exhaustion"; both physical and mental due to work-related stressors [3]. The prevalence of burnout syndrome amongst medical personnel ranges from $27 \%$ to $45 \%$ [4]; and is usually associated with a high prevalence of depression, suicide, use of psychoactive substances, marital problems and professional dysfunction amongst medical personnel [5, 6].

Cameroon which is one of the 57 countries described to have "critical shortages" of healthcare workers [7] has an average health personnel density of 1.3:1000; which is below the WHO recommended of 2.5:1000 [8]. The country has a physician density of approximately 1: 12,500 people [9] which rises to about 1: 26,726 persons in some regions [8]. There is a similar shortage in the health workforce in the nursing department evidenced by a nurses'

\footnotetext{
${ }^{*}$ Correspondence: tsinjim@gmail.com

${ }^{4}$ Health and Human (2HD) Research Network, Douala, Cameroon

Full list of author information is available at the end of the article
}

density of 0.67 per 1000 [8]. With such a high workload, nurses are at risk of having burnout syndrome in Cameroon. There is however a dearth of data in this department as with most mental health issues in Cameroon.

To bridge this gap, we set out to determine the predictors associated with the development of burnout syndrome among nurses working in the two Englishspeaking regions of Cameroon. This could help provide awareness on the existence of the condition and could lead to early detection. It could also help inform policymakers on the need for investigation and institution of appropriate preventive measures.

\section{Main text \\ Methods \\ Study population}

This analysis results from a mental health project which sought to identify predictors of burnout syndrome and depression amongst healthcare workers and students in Cameroon $[10,11]$. Study participants were nurses working in state-owned and private institutions in the two English-speaking regions of Cameroon (North west and South west regions). The number of nurses who work in these two regions is not available. We intended to recruit all the nurses in the sample population. However, the ongoing political crises in the regions resulted in internal 
displacement of most healthcare providers. We were able to approach and include a total of 143 nurses via a consecutive approach.

\section{Study design and protocol}

A cross-sectional analysis carried out over 06 months (January-June 2018) where nurses were approached, and the purpose of the study explained. Those who agreed to participate signed a consent form. They were handed a questionnaire to fill out and return at their earliest convenience.

\section{Study instrument}

The data collection tool was modified from a similar study used to assess burnout and depression amongst nursing students in these regions [11]. Data collected included sociodemographic characteristics [12-14]; assessment of burnout using the Oldenberg burnout inventory (OLBI) and symptoms of depression assessed using the Patient Health Questionnaire-9 form. Responses on the OLBI were expressed on a Likert-scale from one-four corresponding to strongly agree-strongly disagree. The exhaustion and disengagement subscales of the burnout inventory were summed after reversal of negatively phrased questions to obtain a score for the OLBI.

\section{Data management and statistical analysis}

Collected data was entered into EPI Info version 7 for Microsoft windows, and later on exported to the Stata software package version 12 for Microsoft windows for statistical analysis.

Results obtained from the statistical analysis were presented as means (standard deviation; SD) or counts (percentages) where and when appropriate.

Predictors of burnout (assessed as a continuous variable) were determined using univariable analysis (linear regression analysis and comparisons of dependent variable against independent variables using the KruskalWallis test). A multivariable analysis was to be performed if more than two variables were significant on univariable analysis. The threshold for statistical significance was set at $\mathrm{p} \leq 0.05$.

\section{Results}

\section{Sociodemographic characteristics}

A total of 143 nurses were recruited. Most of them were female $(96 ; 67.13 \%)$ (Table 1$)$. The mean age of the participants was $29.75 \pm 6.55$ years (Age range; $20-55$ years) (Table 2).
Table 1 Categorical variables showing the sociodemographic characteristics of 143 nurses in Cameroon assessed for burnout syndrome from January to March 2018

\begin{tabular}{|c|c|c|}
\hline \multirow[t]{2}{*}{ Variable } & \multicolumn{2}{|c|}{ Total } \\
\hline & $\mathbf{N}$ & $\%$ \\
\hline \multicolumn{3}{|l|}{ Hospital $(n=132)$} \\
\hline State-owned & 90 & 68.18 \\
\hline Private sector & 42 & 31.82 \\
\hline \multicolumn{3}{|l|}{ Gender $(n=143)$} \\
\hline Male & 47 & 32.87 \\
\hline Female & 96 & 67.13 \\
\hline \multicolumn{3}{|c|}{ Marital status $(n=142)$} \\
\hline Single & 73 & 51.41 \\
\hline Married & 69 & 48.59 \\
\hline \multicolumn{3}{|c|}{ Personal relationship $(n=127)^{a}$} \\
\hline Yes & 78 & 61.42 \\
\hline No & 49 & 38.58 \\
\hline \multicolumn{3}{|c|}{ Difficulties in personal relationship $(n=118)$} \\
\hline Yes & 26 & 22.03 \\
\hline No & 92 & 77.97 \\
\hline \multicolumn{3}{|c|}{ Majority of shifts $(n=129)$} \\
\hline Day & 99 & 76.74 \\
\hline Night & 30 & 23.26 \\
\hline \multicolumn{3}{|c|}{ Regret career choice $(n=136)$} \\
\hline Yes & 23 & 16.91 \\
\hline No & 113 & 83.09 \\
\hline \multicolumn{3}{|c|}{ Occurrence of life changing crises in last 6 months $(n=139)^{b}$} \\
\hline Yes & 57 & 41.01 \\
\hline No & 82 & 58.99 \\
\hline \multicolumn{3}{|c|}{ Presence of chronic illness $(n=140)^{c}$} \\
\hline Yes & 17 & 12.14 \\
\hline No & 123 & 87.86 \\
\hline \multicolumn{3}{|c|}{ Alcohol consumption $(n=141)$} \\
\hline Yes & 71 & 50.35 \\
\hline No & 70 & 49.65 \\
\hline \multicolumn{3}{|c|}{ Recreational drug use $(n=142)^{d}$} \\
\hline Yes & 7 & 4.93 \\
\hline No & 135 & 95.07 \\
\hline \multicolumn{3}{|c|}{ Sufficient monthly income $(n=133)$} \\
\hline Yes & 13 & 9.77 \\
\hline No & 120 & 90.23 \\
\hline
\end{tabular}

a Personal relationship was defined as close connections between two people formed by emotional and sexual interactions

b Life changing crises defined as loss of a loved one, physical or sexual trauma and condition of emotional or social instability

c Chronic illnesses included: Asthma, chronic pelvic pain, diabetes mellitus, gastroesophageal reflux disease, chronic peptic ulcer disease, migraines, cerebral lesions and paralysis

d Recreational drugs included: marijuana and tramadol 
Table 2 Continuous variables showing the sociodemographic characteristics of 143 nurses in Cameroon assessed for burnout syndrome from January to March 2018

\begin{tabular}{|c|c|c|c|c|c|}
\hline \multirow[t]{2}{*}{ Variable } & \multirow[t]{2}{*}{ Number of observations } & \multicolumn{4}{|c|}{ Total sample } \\
\hline & & Mean & SD & Min & Max \\
\hline Age & 108 & 29.75 & 6.55 & 20 & 55 \\
\hline Number of hours at work a week & 127 & 11.50 & 10.80 & 5 & 90 \\
\hline Monthly income in USD & 58 & 125.15 & 75.79 & 0 & 341.59 \\
\hline Number of night shifts a week & 101 & 2.19 & 1.55 & 0 & 8 \\
\hline Quantity of alcohol consumed a week & 41 & 1.83 & 1.33 & 0.5 & 6.5 \\
\hline Total score for disengagement items & 143 & 17.31 & 3.28 & 8 & 26 \\
\hline Total score for exhaustion items & 143 & 21.05 & 3.46 & 13 & 29 \\
\hline Total OLBI score & 143 & 38.36 & 5.68 & 25 & 52 \\
\hline
\end{tabular}

USD United states dollars, GPA cumulative grade point average, OLBI Oldenburg burnout inventory

Table 3 Univariable linear regression analysis of potential determinants of burnout syndrome amongst 143 nurses who were assessed for burnout syndrome from January to March 2018 in Cameroon

\begin{tabular}{|c|c|c|c|c|}
\hline Variables & Coefficient & Intercept & $95 \% \mathrm{Cl}$ & $p$ value \\
\hline Age & -0.15 & 42.66 & $-0.32,0.02$ & 0.083 \\
\hline Gender (female/male) & -0.98 & 39.02 & $-2.98,1.02$ & 0.334 \\
\hline Marital status (married/single) & -0.39 & 38.56 & $-2.28,1.51$ & 0.687 \\
\hline Personal relationship (yes/no) & 2.31 & 37.04 & $0.28,4.33$ & 0.026 \\
\hline Difficulties in personal relationships (yes/no) & 0.66 & 38.41 & $-1.81,3.14$ & 0.597 \\
\hline Number of children & -0.17 & 38.16 & $-0.84,0.50$ & 0.615 \\
\hline Hospital of practice (private/state-owned) & 1.22 & 37.86 & $-0.90,3.33$ & 0.258 \\
\hline Number of hours spent in hospital & 0.03 & 37.93 & $-0.06,0.13$ & 0.488 \\
\hline Monthly income in USD & 0.001 & 38.80 & $-0.02,0.03$ & 0.921 \\
\hline Sufficient monthly income (yes/no) & 0.51 & 38.42 & $-2.87,3.88$ & 0.767 \\
\hline Majority of shifts (day/night) & -0.38 & 38.55 & $-2.74,1.99$ & 0.752 \\
\hline Number of night shifts a week & 0.61 & 37.08 & $-0.09,1.31$ & 0.085 \\
\hline Regret of career choice (yes/no) & 0.44 & 38.21 & $-2.11,2.99$ & 0.733 \\
\hline Recreational drug use (yes/no) & 3.98 & 38.16 & $-0.35,8.31$ & 0.071 \\
\hline Presence of chronic illness (yes/no) & -0.97 & 38.56 & $-3.89,1.94$ & 0.511 \\
\hline Alcohol consumption (yes/no) & 0.70 & 37.99 & $-1.20,2.61$ & 0.466 \\
\hline Quantity of alcohol consumed & 0.82 & 37.02 & $-0.72,2.35$ & 0.289 \\
\hline
\end{tabular}

\section{Burnout syndrome}

The mean OLBI score was $38.36 \pm 5.68$ (minimum $=25$, maximum $=52$ ) with the mean score for disengagement items being $17.31 \pm 3.28$ ( minimum $=8$, maximum $=26$ ), and the mean score for exhaustion items being; $21.05 \pm 3.46$ (minimum $=13$, maximum $=29$ ) $($ Table 2 ).

\section{Determinants of burnout syndrome}

Determinants of burnout syndrome amongst the recruited nurses as determined by univariable analysis are shown in Table 3 and Additional file 1. Only one variable-being in a personal relationship was significant on univariable linear regression analysis, which predicted $3.8 \%$ of the variation in burnout syndrome as measured using the total OLBI score $\left(\mathrm{R}^{2}=3.8, \mathrm{~F}(1,125)=4.89\right.$, $\mathrm{p}=0.029)$. The regression equation was as follows:

Total OLBI score (burnout syndrome)

$$
=2.25 \text { (being in a personal relationship) }+37.14
$$

\section{Discussion}

Our study was aimed at determining the determinants of burnout syndrome among nurses working in the two English-speaking regions of Cameroon. Results from 
statistical analysis revealed being in a personal relationship as the only significant determinant of burnout.

Our study showed that those in a personal relationship scored about two points higher in the OLBI scale than those who were not in a personal relationship. In effect, being in a relationship could come along with some degree of personal stress related to a variety of items such as the health condition of a loved one and financial strains in the relationship [15]. These stressors (though normal occurrences in a relationship) if not dealt with adequately and promptly could lead to chronic psychological stress which has been shown to be linked to poor physical and mental health outcomes [16-18]. Coupling the above-mentioned stressors resulting from personal relationships with the high workload and high levels of psychological and emotional stressors linked to the nursing profession could prove very difficult to bear. It is therefore not surprising that our study found a positive correlation between being in a personal relationship and burnout syndrome amongst the recruited nurses.

Our results correspond to those obtained by Wang et al. who found a positive relationship between workfamily conflict and emotional exhaustion and cynicism amongst a group of Chinese female nurses [19]. Khamisa et al. found personal stress from relationships to be an accurate predictor of burnout among both male and female South African nurses [20]. Similar findings have been obtained elsewhere [21]. A plausible explanation to this could be the fact that nurses in a personal relationship could find themselves devoting more time and energy in trying to resolve emotional, financial and health problems within their relationships, at the expense of work-related duties. This could in turn lead to quicker exhaustion and cynicism and consequently burnout. Stressors from personal relationships have indeed been shown to interfere with work and cause higher levels of emotional exhaustion and cynicism, hence, higher levels of burnout $[19,20]$.

In this analysis, there was no significant differences in the total OLBI score for nurses who regretted their career choice compared to those who did not. This was contrary to what we found in another study carried out in this project where nursing students who regretted their choice in studying nursing were more likely to have higher burnout scores than those who did not [11]. This could be explained by the fact that most nurses may have already reconciled with their career choices and this will not be a significant predictor of burnout in this population.

Workload was assessed using three variables in this analysis - the number of hours spent in the hospital, the number of night shifts per week and whether most shifts worked were in the night or day. However, all three variables were not associated with burnout syndrome. This was an unexpected finding that should be investigated in future studies.

Seeking social support is seen by some as one of the most important aspect of coping with the stress associated with being in a romantic relationship [22, 23]. However, in developing settings such as ours, social support centres and professionals are far and wide apart, making it difficult for concerned individuals to access the help they need. In addition, the nursing profession is associated with long working hours and a tremendous work load. In settings such as ours where the nurses' density is far below recommended levels [8], working hours and work load increases significantly. In the absence of the necessary professional help, having to deal with the stressors that come along with being in a relationship alone alongside the demands of the nursing profession could prove quite an uphill task. The ultimate result in such cases being quicker exhaustion and consequently burnout. In this light, some studies have found the training of nurses on coping strategies with respect to personal stress as an effective method in preventing burnout and poor mental and physical health outcomes [20, 24].

All these points to the need for more attention to be placed on the mental health status of nurses, and for the facilitation of access to professional help in case of not only work-related but also personal problems which could lead to quicker exhaustion and burnout and eventually decreased performance at work.

\section{Conclusion}

This study could help raise awareness on burnout amongst nurses, and stir up investigations regarding appropriate preventive measures. Determinants presented in this study however require further investigations with larger sample sizes carried out nationwide, to obtain more generalizable conclusions.

\section{Limitations}

Due to the cross-sectional nature of the study, there is the potential for recall bias in the responses of the participants and possible difficulties in ascertaining cause and effect.

Our sample size may not be large or representative enough of the nurses working in the two English-speaking regions of Cameroon as during the study period, there was an ongoing socio-political crisis in these regions of the country leading to displacement of individuals (nurses included), thereby reducing our sampling pool. There is therefore the need to carry out studies using larger sample sizes to make conclusions which could be generalised to the whole country. 
However, to the best of our knowledge, this is the first multicentre study to assess the predictors of burnout syndrome amongst nurses in Cameroon and provides an invaluable insight into the predictors of burnout in this population which could guide future studies.

\section{Additional file}

Additional file 1. Table showing a univariate analysis performed comparing the dependent variable - total OLBI score against the various independent variables using the Kruskal-Wallis test.

\section{Abbreviations}

WHO: World Health Organization; OLBI: Oldenburg Burnout Inventory.

\section{Authors' contributions}

Study conception: TN; Literature search: TN, CM; Data collection: CM, HM, DT, SF, LT; Data management: CM; Data analysis: TN; Initial draft of manuscript; CM, TN; Revision of manuscript; CM, TN, HM, DT, SF, LT; Critical revision of manuscript; TN. All authors read and approved the final manuscript.

\begin{abstract}
Author details
${ }^{1}$ Mankon Sub-Divisional Hospital, Bamenda, Cameroon. ${ }^{2}$ Regional Hospital Bamenda, Bamenda, Cameroon. ${ }^{3}$ Clinical Research Education Networking and Consultancy, Douala, Cameroon. ${ }^{4}$ Health and Human (2HD) Research Network, Douala, Cameroon. ${ }^{5}$ Baptist Hospital Mutengene, Mutengene, Cameroon. ${ }^{6}$ Faculty of Health Sciences, University of Buea, Buea, Cameroon. ${ }^{7}$ Health Education and Research Organization (HERO), Buea, Cameroon.
\end{abstract}

\section{Acknowledgements}

None.

\section{Competing interests}

The authors declare that they have no competing interests.

\section{Availability of data and materials}

The datasets analysed during the current study are available from the corresponding author on reasonable request.

\section{Consent for publication}

Not applicable.

\section{Ethics approval and consent to participate}

Data was collected only from nurses who had provided written consent to participate in the study. Confidentiality was equally assured by collecting data anonymously. All information obtained during this study was used for the sole purpose of the study. Ethics approval was obtained from the Cameroon Baptist Convention Institutional Review Board and Administrative authorization was obtained from the directorate of each of the institutions used as recruitment sites for the study.

\section{Funding}

None.

\section{Publisher's Note}

Springer Nature remains neutral with regard to jurisdictional claims in published maps and institutional affiliations.

Received: 8 October 2018 Accepted: 10 December 2018 Published online: 14 December 2018

\section{References}

1. Demerouti E, Bakker AB. The Oldenburg Burnout Inventory: a good alternative to measure burnout and engagement. Handbook of Stress and Burnout in Health Care. 2008.

2. Maslach C, Schaufeli WB, Leiter MP. Job burnout. Annu Rev Psychol. 2001;52:397-422.

3. World Health Organisation. ICD-10. Geneva: WHO; 2016. http://apps.who. int/classifications/icd1 1/browse/2016/en\#/Z73.0. Accessed 26 Oct 2018.

4. Martini S, Arfken CL, Churchill A, Balon R. Burnout comparison among residents in different medical specialties. Acad Psychiatry. 2004;28(3):240-2.

5. Voltmer E, Kieschke U, Schwappach DL, Wirsching M, Spahn C. Psychosocial health risk factors and resources of medical students and physicians: a cross-sectional study. BMC Med Educ. 2008;8:46.

6. Costa EF, Santos SA, Santos AT, Melo EV, Andrade TM. Burnout Syndrome and associated factors among medical students: a cross-sectional study. Clinics (Sao Paulo). 2012;67(6):573-80.

7. Global health work force. Health workers for all and all for health workers: The human resource for health crisis. Geneva: World Health Organisation; 2013.

8. Tandi TE, Cho Y, Akam AJ, Afoh CO, Ryu SH, Choi MS, et al. Cameroon public health sector: shortage and inequalities in geographic distribution of health personnel. Int J Equity Health. 2015;14:43.

9. Agency TWFCl. Africa: Cameroon 2017. https://www.cia.gov/library/publi cations/the-world-factbook/geos/cm.html. Accessed 16 Dec 2017.

10. Mbanga CM, Efie DT, Aroke D, Njim T. Prevalence and predictors of recreational drug use among medical and nursing students in Cameroon: a cross sectional analysis. BMC Res Notes. 2018;11 (1):515.

11. Njim T, Mbanga C, Mouemba D, Makebe H, Toukam L, Kika B, et al. Determinants of burnout syndrome among nursing students in Cameroon: cross-sectional study. BMC Res Notes. 2018;11(1):450.

12. Brandford AA, Reed DB. Depression in registered nurses. A state of the science. Workplace Health Saf. 2016;64(10):488-511.

13. Ngasa SN, Sama CB, Dzekem BS, Nforchu KN, Tindong M, Aroke D, et al. Prevalence and factors associated with depression among medical students in Cameroon: a cross-sectional study. BMC Psychiatry. 2017;17(1):216.

14. Geisner IM, Mallett K, Kilmer JR. An examination of depressive symptoms and drinking patterns in first year college students. Issues Ment Health Nurs. 2012;33(5):280-7.

15. Bromberger JT, Matthews KA. A longitudinal study of the effects of pessimism, trait anxiety and life stress on depressive symptoms in middleaged women. Psychol Aging. 1996;11:207-13.

16. O'Donovan R, Doody O, Lyons R. The effect of stress on health and its implications for nursing. Br J Nurs. 2013;22(16):969-73.

17. Young M, Schieman S, Milkie MA. Spouse's work-to-family conflict, family stressors and mental health among dual-earner mothers and fathers. Soc Ment Health. 2013;4(1):1-20.

18. Killien MG. Nurses' health: work and family influences. Nurs Clin North Am. 2004;39(1):19-35.

19. Wang Y, Chang Y, Fu J, Wang L. Work-family conflict and burnout among Chinese female nurses: the mediating effect of psychological capital. BMC Public Health. 2012;12(1):915.

20. Khamisa N, Peltzer K, llic D, Oldenburg B. Effect of personal and work stress on burnout, job satisfaction and general health of hospital nurses in South Africa. Health SA Gesondheid. 2017;22:252-8.

21. Yavas U, Babakus E, Karatepe OM. Attitudinal and behavioral consequences of work-family conflict and familywork conflict. Does gender matter? Int J Serv Ind Manag. 2008;19(1):7-31.

22. Cohen J. Statistical power analysis for the behavioural science. New Jersey: Lawrence Enlbaum Associates; 1988.

23. House JS, Landies KR, Umberson F. Social relationship and health science. Science. 1988;241:540-50

24. Ford MT, Heinen BA, Langkamer KL. Work and family satisfaction and conflict: a meta-analysis of crossdomain relations. J Appl Psychol. 2007;92(1):57-80. 